Sandra REINEKE, Beauvoir and her Sisters. The politics of women's bodies in France

Urbana, University of Illinois Press, 2011, 128 p.

\title{
Marine Rouch
}

\section{CpenEdition}

Journals

Édition électronique

URL : http://journals.openedition.org/clio/13081

DOI : 10.4000/clio.13081

ISSN : 1777-5299

Éditeur

Belin

Édition imprimée

Date de publication : 1 juin 2016

Pagination : 341-341

ISBN : 978-2-7011-9852-1

ISSN : 1252-7017

Référence électronique

Marine Rouch, "Sandra ReInekE, Beauvoir and her Sisters. The politics of women's bodies in France », Clio Femmes, Genre, Histoire [En ligne], 43 | 2016, mis en ligne le 07 juillet 2016, consulté le 23 septembre 2020. URL : http://journals.openedition.org/clio/13081; DOI : https://doi.org/10.4000/clio.13081

Ce document a été généré automatiquement le 23 septembre 2020.

Tous droits réservés 


\section{Sandra REINEKE, Beauvoir and her Sisters. The politics of women's bodies in France}

Urbana, University of Illinois Press, 2011, 128 p.

Marine Rouch

\section{RÉFÉRENCE}

Sandra Reineke, Beauvoir and her Sisters. The politics of women's bodies in France, Urbana, University of Illinois Press, 2011, 128 p.

1 Alors que beaucoup d'études mettent l'accent sur le moment et la façon dont les femmes participent politiquement en tant que citoyennes, Sandra Reineke s'intéresse plutôt au passage des femmes du statut de citoyennes à celui d'agents politiques. Aussi la question de la performativité des actes de lecture et d'écriture par les femmes estelle posée et discutée.

2 Les femmes auraient fait de la lecture et de l'écriture des vectrices de l'idée de communauté. Celle-ci serait caractérisée par une identité féminine et des intérêts politiques communs, principalement autour des questions de sexualité et de droits reproductifs de l'après-guerre aux années 1990. Pour donner à un simple sentiment, diffus et difficilement palpable, une réalité effective, Sandra Reineke convoque le concept politique d' « imagined sisterwood» (" sentiment de sororité ») qui aurait aidé et permis aux femmes de s'affirmer dans les différentes strates de la politique. L'ouvrage prétend mettre en lumière le processus de création par les femmes de cette sororité pour s'exprimer, à partir de 1944, dans ce royaume éminemment masculin qu'est l'espace public, la politique en premier lieu.

3 «Sisterwood» est employé pour se référer à un réseau qui promeut la conscience à la fois féminine et féministe ainsi que l'activisme féministe. Ses racines se situent à la fin $\mathrm{du} \mathrm{XVIII}^{\mathrm{e}}$ siècle, au moment où la culture a connu une division selon des règles de genre 
et que les femmes et les hommes ont été assignés à des sphères distinctes d'activité. Paradoxalement, le présupposé selon lequel la sphère et la culture féminines étaient supérieures à celle des hommes était reconnu puisque les femmes étaient considérées comme les garantes des bonnes valeurs morales. C'est donc à partir de la formation de cette idée que l'on entrevoit clairement, selon S. Reineke, le phénomène de sororité. Il aurait ensuite fallu attendre Simone de Beauvoir et plus précisément son Deuxième Sexe (1949) pour que les femmes l'interprètent en concept. Ainsi, les femmes activistes, à partir de la fin des années 1960 et dans leur effort d'incarner la citoyenneté, ont forgé une identité politique et collective féminine et féministe.

4 Toutes ne la ressentaient cependant pas, d'où l'adjectif, "imagined», que Sandra Reineke a choisi d'accoler au concept. En cela réside la nouveauté puisqu'il permet au fil de l'étude de faire le lien entre les pratiques du militantisme féministe et les femmes non activistes, plus touchées par la culture de masse que par les moins accessibles productions féministes. Le concept d'« imagined sisterwood » est donc utilisé pour mieux comprendre la façon dont les citoyennes forgent une conscience politique commune leur permettant d'agir collectivement à travers deux pratiques du quotidien : la lecture et l'écriture.

5 Trois niveaux de ces activités sont analysés : la littérature féministe intellectuelle, la presse populaire féminine de masse et les journaux militants féministes. Reineke souhaite montrer combien les écrits des femmes ont participé à la lutte politique et au sentiment de sororité. Les problématiques liées au corps des femmes, la sexualité en premier lieu, ont été à l'origine de riches échanges dans l'espace public. Dans cette vaste entreprise, l'ambiguïté des magazines populaires féminins (Elle, Marie-Claire) se fait sentir: tout en relayant les luttes des femmes quant à leur propre corps, des impératifs financiers les ont forcés à assumer leur rôle au sein de la société de consommation en présentant le corps féminin comme un objet de désir et une cible de consommation. L'ensemble des écrits étudiés sont autant d'exemples de la volonté d'un changement sociopolitique au terme duquel les femmes auraient eu accès à un nouvel espace distinct de leur espace traditionnel.

6 L'originalité de l'étude réside dans la méthode employée. L'auteure a procédé à une analyse qualitative de discours politique dans les écrits de femmes selon les conceptions de la Cambridge School de Skinner qui a démontré la nécessité de remettre la pensée politique dans son contexte social et culturel. L'auteure ne cesse jamais de connecter les pratiques sexuelles et le corps des femmes à des politiques plus générales et à des revendications plus particulières et libératrices. L'accent est d'ailleurs mis sur la construction genrée de la citoyenneté puisque les pratiques corporelles et les revendications qui lui sont liées diffèrent selon que l'on est homme ou femme. Il peut cependant paraître regrettable que les sources soient si peu citées. La méthode employée est certes limpide puisqu'elle est régulièrement rappelée mais cela implique malheureusement un manque de proximité des documents et des résultats obtenus au terme de l'analyse.

7 L'ouvrage a également sa place dans le courant de la renaissance des études beauvoiriennes qui depuis le début des années 1990 s'est caractérisée par la volonté des universitaires de dépasser les clivages à la fois féministes et philosophiques. Reineke accorde à Beauvoir une influence sur ses descendantes aujourd'hui encore peu sereinement et objectivement explorée. La philosophe aurait été de manière inconsciente l'inspiratrice d'un sentiment d'identité féminine collective grâce à la 
publication du Deuxième Sexe qui a permis l'engagement d'un discours sur la sexualité et sur les droits reproductifs, discours qui n'a réellement pris de l'ampleur qu'une décennie plus tard. L'on peut à nouveau regretter que l'auteure, après avoir émis cette hypothèse, ne revienne pas une seule fois sur le lien qu'elle entrevoit entre Le Deuxième Sexe, la vie de Simone de Beauvoir et cette « imagined sisterwood».

Sandra Reineke se place dans deux veines des récentes contributions à ces études: la première est l'héritière de Margaret Simons et de ses travaux d'exploration de la relation philosophique qui unissait Beauvoir et Sartre. La seconde correspond aux études sur le corps de la femme dans la philosophie beauvoirienne. Mais Reineke a tendance à présenter Beauvoir comme critique féministe française de l'après-guerre alors que l'on sait que la philosophe n'a pas écrit son Deuxième Sexe dans une perspective féministe et que l'on date sa prise de conscience féministe, au sens militant que nous lui donnons aujourd'hui, de la fin des années 1960 et du début des années 1970 , quand elle a choisi de relayer les combats du MLF. De plus, au cours d'un rappel biographique sur la philosophe (p.22), S. Reineke se calque complètement sur ses mémoires. De fait, elle ne doute pas une seule fois que Beauvoir a pu souffrir d'être femme et écrit, comme Beauvoir le suggère dans ses mémoires mais aussi dans divers entretiens, qu'elle a réussi à dépasser sa condition en se faisant "femme exceptionnelle ». Quelques réserves pourraient être émises quant à ces affirmations, à la fois de Beauvoir et de Reineke. Il suffirait de rappeler les caractéristiques du genre de l'autobiographie et du célèbre pacte autobiographique de l'auteur, dont celui des Confessions de Rousseau est un bel exemple, pour remettre en question la sincérité d'un.e écrivain.e. Il faudrait encore creuser du côté de l'inclination de Beauvoir pour les thèmes qu'elle traite pour se rendre compte que la sexualité et les femmes ne sont pas des sujets innocemment choisis. Une telle entreprise tendrait vers une histoire à tendance psychologisante dont la richesse ni la rigueur ne sont à négliger.

Il n'en reste pas moins que la notion d'« imagined sisterwood " permet de découvrir sous un nouveau jour l'organisation des moyens employés par les femmes lors des grandes batailles féministes à partir des années 1970. Reineke montre la richesse des récents développements théoriques concernant la sexualité, les femmes et le corps. Il en est un, au centre du propos, qui démontre qu'en termes de représentation, le corps des femmes est, comme le MLF l'avait suggéré, bien plus qu'une entité biologique : il est le lieu de contestations politiques et ce, encore aujourd'hui.

\section{AUTEUR}

\section{MARINE ROUCH}

Université Toulouse-Jean Jaurès(Framespa)Lille 3 (ALITHILA) 